South African Journal of Geomatics, Vol. 7. No. 3, November 2018

\title{
Network Database Design for Conflict and Post-Conflict Land Tenure Information Systems (LTIS)
}

\author{
Alaa Dabboor ${ }^{1}$, Michael Barry ${ }^{2}$ \\ ${ }^{1}$ MSc. in Geomatics Engineering, Specialization is GIS and Land Tenure, Geomatics Engineering \\ Department, University of Calgary, Canada, addabboo@ucalgary.ca \\ ${ }^{2}$ Professor and Chair in Land Tenure and Cadastral Systems in the Geomatics Engineering Department, \\ University of Calgary, Canada, mbarry@ucalgary.ca
}

DOI: http://dx.doi.org/10.4314/sajg.v7i3.8

\begin{abstract}
The paper presents the Talking Titler Network (TTN) database design for land records in complex situations. In conflict and post-conflict situations, conventional land record database models are limited in how they can handle the complex constellations of interests in particular land units. One solution is a network database model that can capture multiple, overlapping and layered tenure relationships in a changing environment which can be augmented by data mining and social network analysis to overcome the limitations of the relational data model in handling complex, competing evidence. The Triple Store graph database development system and its ontology languages were used to design and develop the TTN prototype. The authors' observations from the Gaza Strip, an ongoing conflict situation, and Somaliland, a post-conflict situation, were used as illustrative contexts. The test results show that graph database flexibly captured, described, and automatically revealed tenure patterns. TTN simplified the complexity of tenure relationships among objects by organizing them into sets of connected triples, revealing tenure relationships, and visualizing tenure information as a graph network, and as a table. The initial design shows promise in capturing and revealing relationships in complex, contested tenure scenarios.
\end{abstract}

\section{Introduction}

It is seldom feasible to apply conventional land tenure administration approaches to conflict and postconflict environments as these may bias the holding of property rights in favour of particular groups, introduce inefficiencies, and possibly exacerbate the situation (Augustinus and Barry 2006). In conflict and post-conflict situations, tenure disputes pose serious challenges for tenure security, peace-building, and recovery (Barry et al., 2014; Unruh 2016). Of relevance for tenure information systems are the overlapping, contested land claims which pose distinctive challenges for land tenure information database design. The article describes an adaptive and flexible semantic Land Tenure Information System 
(LTIS) database design, the Talking Titler Network (TTN), which is designed to capture structured and unstructured data and represent tenure relationships that may be too complex for a relational database to handle. The TTN prototype uses a schema-less design model implemented in a graph network database, which should be better suited to complex tenure situations (Strauch 2009; Zicari 2015). It also incorporates rudimentary data mining (DM) and social network analysis (SNA) techniques. The prototype was developed using simulated data that draw on the first author's observations as a researcher and a resident of Gaza, Palestine, and the second author's work in post-conflict land administration strategy formulation in Hargeisa, Somaliland.

Most LTIS software, such as the Social Tenure Domain Model (STDM) - a specialisation of the descriptive ISO standard (19152) Land Administration Domain Model - uses the relational database model. The relational model may be ill-suited to the complexity inherent in some conflict and postconflict situations, where numerous many-to-many relationships may be represented in unstructured and conflicting data. It is also poor problem solving and strategy formulation practice to constrain a solution by adopting a particular database model or a universal standard upfront without first examining the different LTIS alternatives that may best fit a problem situation (Barry and Asiedu 2016).

The paper proceeds by describing conflict and post conflict situations, the situations in Hargeisa, Somaliland and Gaza, Palestine. The TTN database design model and the Social Network Analysis and Data Mining functionality is presented after this. The TTN development methodology is then described, followed by a discussion of the tests on the prototype.

\section{Conflict and Post-Conflict Situations}

It may be difficult for an outside agent to fully understand the tenure problems at hand in a conflict/post-conflict situation. Often the interrelationships between behaviours on the ground and various interwoven local and wider political and social forces are not clearly apparent. A land tenure information system design that may support an equitable, long term resolution of the situation should cater for possible land invasions, land grabbing by powerful elites within sub-clans and armed factions, forceful evictions, informal settlement by internally displaced persons (IDPs), and the assumption of authority by illegitimate groups and individuals (ODI 2009; Koek et al. 2015; Unruh 2016). In addition, conflicts over land and inheritance may arise within families and sub-clans.

Restitution is a major challenge in peace-building and recovery efforts following conflict (Muhsen and Barry 2008, Unruh 2016). Land and property restitution claims arise, for example, when displaced people attempt to return to their places of origin to find them occupied and claimed by others and when different members of a family or sub-clan lay claim to property. Multiple sets of land records may be held by state and private agencies and individuals, and numerous fraudulent documents may exist (Augustinus and Barry 2006). Much of the relevant evidence of land interests may be in the form of 
structured, semi-structured, and unstructured data. Nowadays, refugees may use online social network applications (e.g., Facebook, Twitter, and WhatsApp) to collect evidence about their properties while they are in refugee camps. These data include pictures and video and audio recordings from neighbours and other important actors (Unruh 2016). Capturing and organising data that reflects the competing claims by all interested parties may reduce the number and intensity of land conflicts. The task of evaluating which data are authentic and the hierarchy of rights and powers over land when there are overlapping interests is part of the challenge. Ideally it is best to capture all the interests claimed as the data become available, starting when it is apparent that conflict is likely to occur, rather than waiting for a restitution and dispute resolution process to commence after a conflict has subsided. Capturing the full spectrum of claims should mitigate the risk of assigning tenure certificates to a group that may not have a legitimate primary claim to contested land. As Alden Wily (2004) observes, certifying land rights in the names of the "wrong" group may catalyse further conflict.

We now briefly describe Hargeisa, Somaliland and Gaza, as these contexts were used to simulate data to design and develop the prototype TTN database. Somaliland has been a self-declared country, since 1991. The capital city, Hargeisa, was occupied during civil war between 1988 and 1990, large numbers were killed and there were major human rights violations. A large Somaliland diaspora in Europe and North America is a consequence of people fleeing the conflict. The diaspora continue to influence property rights matters within families in Hargeisa. In addition, IDPs from other parts of Somalia moved to Hargeisa to escape the violence in their territories. Land disputes were a major problem in Hargeisa involving disputes within families, between sub-clans, and state organisations and sub-clans. Land grabs using erroneous or fraudulent deeds were not uncommon. Disputes occasionally ended up in stand offs where opposing parties hired militias, firearms were brandished and one side backed off or a fire fight erupted. Many people lost their title deeds in the civil war. Subsequently, more than one legal document might exist for the same piece of land due to errors by the authorities or fraud. Newcomers invaded land vacated by people who fled the civil wars and tried to appropriate it for themselves. There were also cases of people selling the same piece of land to more than one buyer. Family conflicts occurred where a person sold a piece of land in which other family members believed they had an interest, and in their opinion the seller was not entitled to sell the land without consulting all the interested parties in the family. The family then attempted to reclaim the land from the buyer. There were also boundary disputes, allegedly caused by people moving their neighbour's boundary beacons. Lastly, there were disputes between government departments and the municipality over who owns a piece of land, and the municipality allocating land or merely using it without ascertaining who owns it (Barry 2006, Barry M. and Bruyas F. 2009).

In Gaza, there has been significant property destruction and increasing numbers of IDPs because of the ongoing conflict between Israeli and Gazan fighters (Koek, Arafat, and Clutterbuck 2015). Some $70 \%$ of private land in the Gaza Strip is unregistered. There are ongoing conflicts due to attempts to 
invade and grab land, boundary disputes and inheritance disputes within families (Dabboor 2017). Restitution processes are at a standstill due to land tenure conflicts between people who have lost their properties and the difficulty in identifying rightful landowners (Koek et al. 2015).

From the above, the challenge then is to create a LTIS that can be used for day to day tenure administration and to provide evidence for resolving land claims and land restitution cases.

\section{TTN Database Design Model}

Using conflict and post-conflict situations to guide the design, the TTN database comprises classes and sub-classes, where each class describes a set of objects (nodes) such as people, land, and documents. Portrayed in Figure 1, the TTN database model consists of a primary class, A TenureTransaction and/or claim that is linked directly to five other main classes: Person/Tenant, Person, TenureObject, SupportingDocuments, and Date. In addition, the TTN conceptual model contains a fundamental class, LandTenureCase that is linked to the $A$ TenureTransaction and/or claim class through the Person/Tenant class.

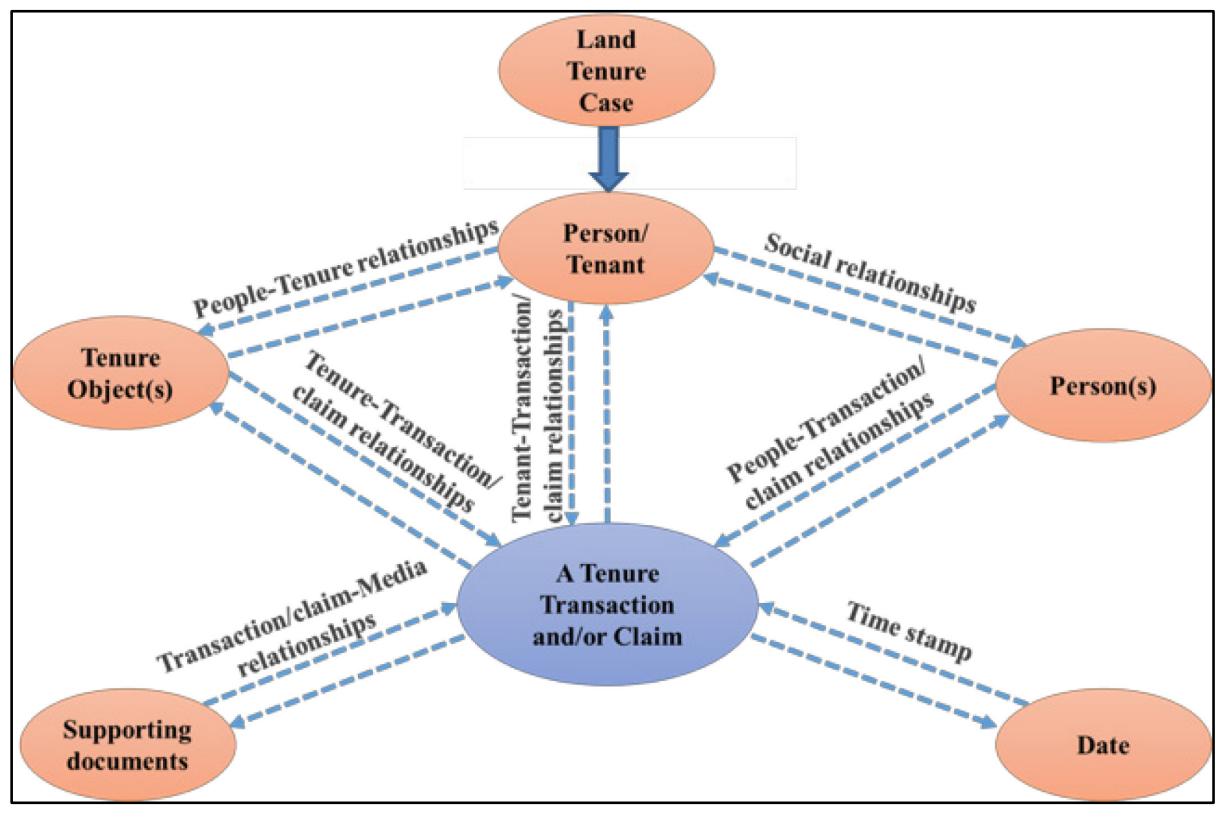

Figure 1. TTN database Design Model

The conceptual model represents a tenure relationship as a set of triples. Each triple consists of two nodes, and a unidirectional link. The subject node (source node) and object node (destination node) is connected by a unidirectional link (relationship). A node describes a tenure object (Land Object) or a person, whereas the link describes the relationship between the two nodes (see figure 2). Modelling tenure relationships in this way allows the system to capture and manipulate unstructured data, and dynamically represent complex land tenure relationships. 
A tenure scenario can be described by a set of sentences. The simplest form of a sentence consists of three main components: subject, verb, and object (See Figure 2). The Triple Store database has the same form (structure) where it captures the subject in the source node, the object in the destination node, and the verb in the unidirectional link.

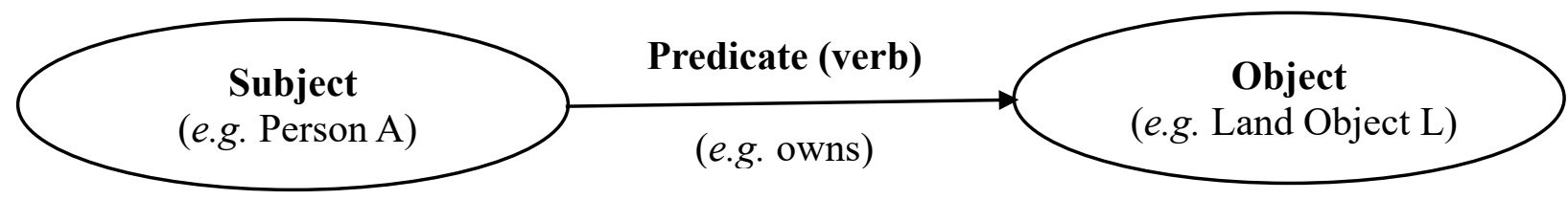

Figure 2. Triple Store Database Structure

In TTN tenure scenarios are expressed as a series of transactions and claims during different epochs, and the multiple roles that a person may have are represented in different scenarios through these transactions and claims. It is important to regard tenure transactions and claims as a separate class (entity) that are interconnected with all other classes (entities) in the TTN database, in order to simplify the complexity of tenure relationships. All of the primary and the main classes in the TTN database, except the Date class, include relevant sub-classes that automatically classify tenure data based on their relationships. The Date class is a key class in the TTN system, as it can be used to show the different time stamps of events in a land dispute scenario.

As tenure relationships become dynamic and fluid in conflict and post-conflict conditions, a potential set of tenure sub-classes of the primary and the main classes (e.g. land type and customary laws) and relationships were considered in the TTN database in order to support the TTN's adaptation to these situations. Portrayed in Figure1, the following are the primary and the main classes of the TTN database model:

1. LandTenureCase: is a tenure scenario that captures and describes a tenure claim and relevant tenure historical claim(s) and/or transaction(s). This class consists of different sub-classes to capture and describe the different aspects of a tenure scenario such as the area of the conflict, the unique land tenure case Identification (ID) of the case, the alias of a land tenure scenario, and the brief description of the case.

2. Person/Tenant and Person: these classes describe the different social roles that a person may have in a land tenure scenario. The Person/Tenant class describes the person who is a tenant in a specific scenario, while the Person class is for capturing and describing the social roles of people who have relationships with the tenant (e.g. witness) and with their family members (e.g. father or mother). Plural roles needs to be captured and described well, especially in inheritance disputes. The Person class consists of sub-classes to describe different social roles.

3. TenureObject: captures and describes different types of tenure objects (e.g. a land object and a development). The development type consists of many sub-types: cultivated field, fruit trees, building, shelter, shop, house, apartment, and garage. Tenure objects are distributed among 
these classes based on their relationships. The TenureObject class consists of different subclasses to describe the different types of tenure objects.

4. SupportingDocuments: captures and describes different types of supporting documents that can be used to support a claim or a historical tenure transaction such as, deeds, scanned documents, pictures, and videos.

5. TenureTransaction and/or claim: captures and describes the possible formal and informal historical tenure transactions such as expropriation, inheritance, rent, purchase/sell, and suspension. Also, it captures and describes different types of claims including ownership, inheritance, and rent between individuals on a tenure object. Therefore, this class consists of different subclasses which describe the different types of tenure transactions and claims.

Individuals can be distinguished based on their relationships within and between different classes. The relationships between individuals in a class were described through unidirectional links, where each link has a source node and a destination node. The node within this context is an individual person or a legal person.

Different types of significant tenure relationship in conflict and post-conflict situations were considered in the TTN database model. One of these types is an asymmetric relationship. This relationship type describes relationships between two parts which are not interchangeable, such as a relationship between a landlord and a tenant, or a son and his father. These types of relationships need to be described clearly, as there may be risks of inconsistencies in the database if they are not. For instance they may form the basis of inheritance claims.

Various types of social and tenure relationships were defined, such as: person-person, person-tenure object, person-tenure transaction, person-claim, person-land tenure, object-tenure transaction, tenure object-claim, supporting document-tenure transaction, and supporting document-claim. Capturing this range of tenure relationships is significant in highlighting different tenure relationship rules for the settlement of tenure claims (Barry et al. 2013).

\section{Data Mining and Social Network Analysis}

The data mining technique applied in the TTN database prototype is rudimentary. It extracts hidden relationships in the data through connections (e.g. grandfather - daughter) which are not explicitly defined in the data entry process. The social network analysis technique applied in the TTN database can be described as a technology used to predict or discover social behaviour trends in order to visualise the constellation of social interests in a particular situation by analysing relationships among people that give rise to rights and interests in particular pieces of land (Barry 2015, Dabboor 2017; Zaki and Meira 2014, Butts 2008). 
Data mining and social network analysis techniques can facilitate a better understanding of claims which are complex and convoluted. The database can illustrate relationships between different family members, clans/sub-clans, and property transactions by showing the different levels of relationships between family members to other family members, family to family, family to clan, and clan/sub-clan to clan. Furthermore, the database can highlight individuals who may have an influential role in dispute resolution, such as specific elders or family members. This is important for conflict resolution processes because it identifies the significant actors and relationships. Persons who are likely to have an impact or influence in creating land conflicts (e.g a warlord) or resolving claims (e.g. a mediator, land surveyor) who are not explicitly identified as such during data entry may be identified through data mining, ideally reducing the likelihood of resistance and new claims (Barry and Asiedu 2016, Dabboor 2017).

\section{TTN Development Methodology}

To support the development of the initial design of the TTN database design model and the integration of data mining and social network analysis techniques, the Triple Store database system — a Not Only Structured Query Language (NoSQL) database system - and its ontology languages, Resource Description Framework (RDF) were used for modelling tenure data in binary relations. Resource Description Framework Schema (RDFS) and Web Ontology Language (OWL) were used to add semantics to the RDF data model by providing a vocabulary of terms that can be used in RDF statements. Triple Store is supportive of web-based database design, where it is mainly used for semantic web database design (W3C 2013, Ontotext 2014).

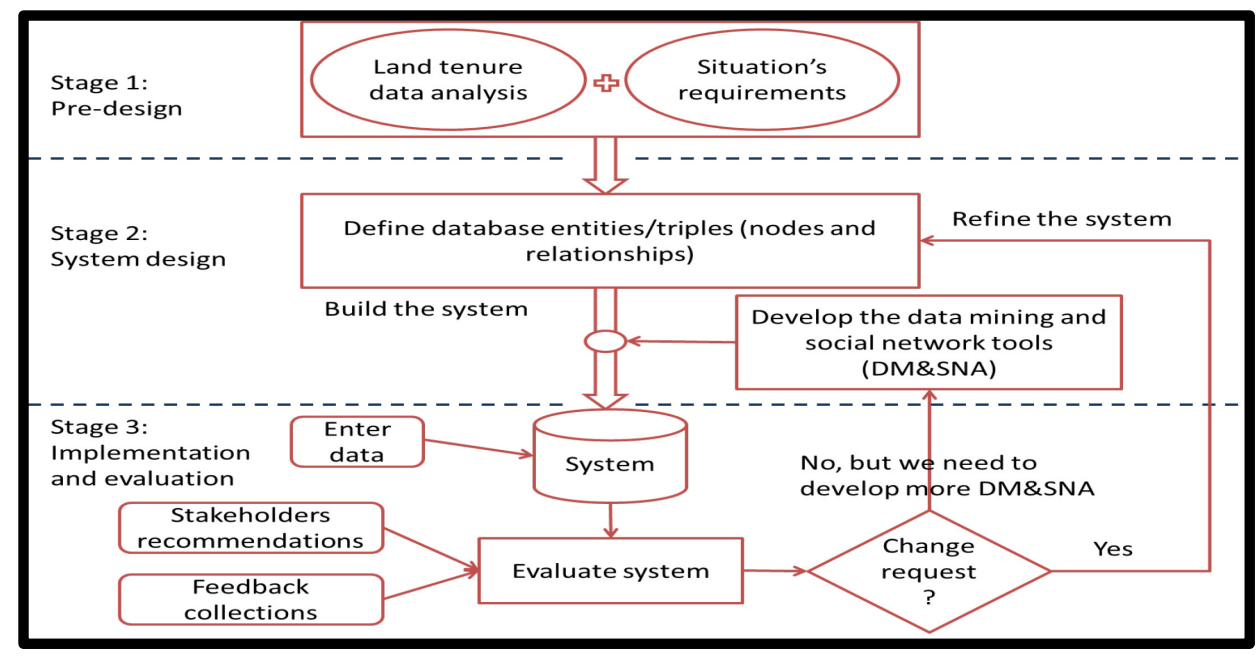

Figure 3. TTN Database Development Methodology

The TTN operational system can be gradually evolved and refined over time to fit the requirements of a particular situation incrementally. Figure 3 describes the database design methodology used. It 
consists of three main stages: (1) pre-design stage, (2) system design, and (3) implementation and evaluation.

Stage 1, the pre-design stage, begins by describing the characteristics of a conflict or post-conflict situation. Then, it determines the desirable features of the TTN database. The main features of the TTN database are focused on: flexibility in capturing and describing land tenure information; the ability to support and facilitate data mining and social network analysis processes; and the ability to permit further development without causing the database design to collapse.

Stage 2, the system design and development stage, describes the technical design of the TTN database prototype, and how the desirable features of the design were achieved. The Triple Store database was used to design the database by creating node and unidirectional relationships. Triple Store was used because it supports graph network management and provides an acceptable degree of robustness through its ability to handle billions of nodes and relationships. To develop the TTN database design, RDF, RDFS, and OWL triple store ontologies were used to create the TTN database nodes and unidirectional relationships (links) in the form of classes and sub-classes. Protégé 4.3 software, an open-source ontology editor and framework for building intelligent systems, was used to develop the TTN database as it compiles RDF, RDFS, and OWL (Stanford University 2016). Also, the Protégé software has an interface for data entry, which was used to test the TTN database prototype (Stanford University 2016). Data is structured in the TTN database in the form of classes and sub-classes that were defined according to the conflict and post-conflict situations described in section 2. For example, the Person class includes the following set of sub-classes: Parent, Daughter, Father, Mother, and Son. The TTN database classes and sub-classes are defined based on their relationships. Figure 4 shows how the database defines the Parent class. As shown in figure 4, the TTN database describes the person as a parent if the person is a member of the Person class and has a hasChild relationship with another person that is member of the Person class as well. This relationship is defined in the form of a triple (subject, predicate, and object) and modelled using the RDF ontology language.

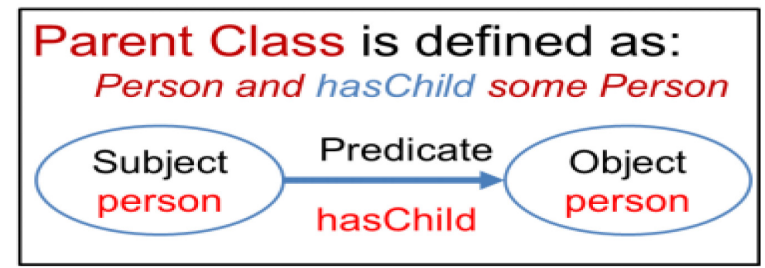

Figure 4. Parent Class Definition - TTN Database

Regarding tenure relationships, the TTN database uses two types of relationships to model tenure relationships. The first type is an Object Property relationship, which describes tenure relationships between objects. The second type is a Data Property relationship, which describes tenure relationships 
between objects and values (e.g. number and string). Figure 5 shows an example of how the TTN database models tenure relationships using the Object and Data Property relationships.

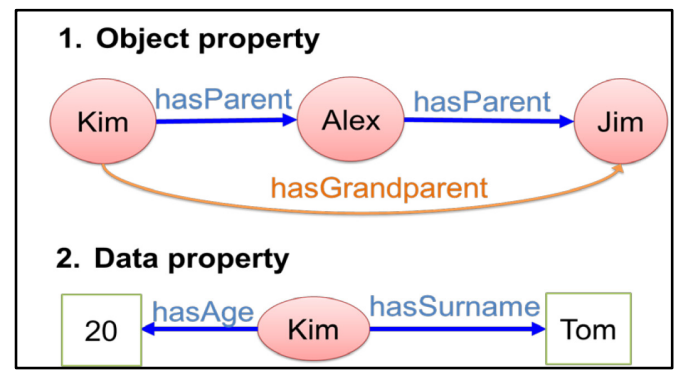

Figure 5. TTN Database Modelling

As shown in figure 5, the Object Property relationship is used to model different relationships between different persons: Kim, Alex, and Jim. The blue unidirectional link that is labelled as hasParent describes the parent-son relationship. Figure 5 shows that Alex is the parent of Kim and the son of Jim. The orange unidirectional link is the relationship inferred by the TTN database based on a chain of two hasParent relationships. The inferred relationships describe a grandparent-grandchild relationship between Kim and Jim. Regarding the Data Property relationship, figure 5 shows an example where the personal information about Kim, surname and age are described.

The TTN database captures and describes tenure information in the form of triples modelled by RDF. For example, Kim has a parent named Alex. The TTN database captures and stores this information in the following way: Kim hasParent Alex Kim is the subject, hasParent is the predicate, and Alex is the object. The TTN database stores data into one text file. Figure 6 shows, as an example, describes how the TTN database captured and stored the two hasParent relationships, and inferred the has Grandparent relationship using RDF, RDFS, and OWL ontology languages.

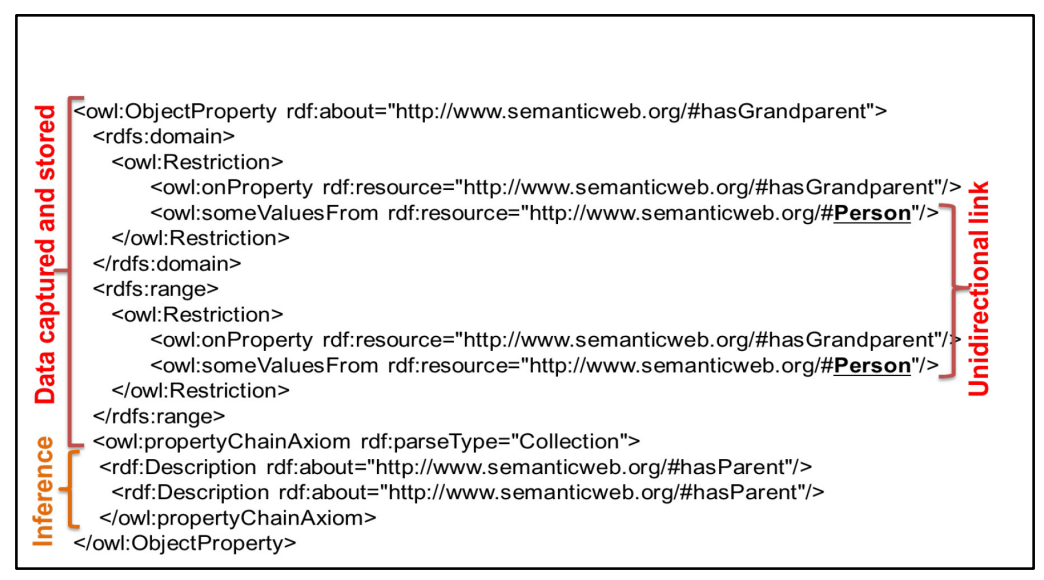

Figure 6. The hasGrandparent Relationship

The section in the code above labelled "Data captured and stored" shows how the TTN database captured and stored the hasParent relationships, while the section in the code labelled "Unidirectional 
link" shows how these relationships are captured and described in a unidirectional way. The last few lines of the code illustrate how the database inferred the hasGrandparent relationship from the two hasParent relationships.

Stage 3, the implementation and evaluation stage, supports the prototype's modification(s) required at runtime in response to needs/recommendations introduced by stakeholders. As shown in figure 3, stakeholders' recommendations can be implemented in "Change request?" which allows for two types of refinement in the implementation and evaluation stage. Refinement is determined through the following two output choices that link stage 3 back to stage 2 :

1. "Yes" allows the TTN database to be refined through the addition of more nodes and links that are required for capturing new types of tenure information.

2. "No, but we need to develop more data mining and social network analysis (DM\&SNA)" means that there is no need to refine the TTN database itself, but more data mining and social network analysis tools are required.

The evolutionary development process supports the adaptation of the TTN database in conflict and post-conflict situations.

In addition to the above, the TTN was designed to visualize explicit and implicit tenure information in different ways. The different ways of visualizing tenure information support the TTN database's flexibility in describing tenure information and further enables stakeholders to trace inheritance patterns, and to focus on the core elements of a network in order to investigate specific claims and relationships. For instance, the TTN database can visualize tenure relationships in hierarchal structure modes (e.g. Tree-Vertical structure, Tree-Horizontal structure, Vertical Directed structure, Horizontal-Directed structure) which help stakeholders understand tenure relationships in an inheritance tenure claim. It can also visualize tenure information in a star (e.g. Radial) mode, which creates a visual of the stakeholders' relationships to a selected tenure object.

\section{TTN Database Test and Results}

The TTN prototype was tested using the simulated dataset described below using The Protégé software by applying the process in Figure 7 below. The purpose of this test was to determine if the TTN database captures and describes the complex land tenure information and automatically investigates the tenure network and reveals hidden tenure information.

Tenure data/elements from a data set generated from the Gaza and Somaliland scenarios were selected and entered as instances of the following classes: Person/tenant; Tenure transaction and/or claim; Tenure object; and Supporting documents into two separate TTN databases. The corresponding tenure relationships were established. For example, each tenure transaction or claim has supporting documents, a date, tenure objects, and so forth. The TTN database was refined iteratively to capture new tenure 
objects as subclasses of the defined classes and to capture relationships in the two scenarios that had not been considered in the initial TTN database design. In addition, data mining and social network analysis techniques were adjusted in order to consider the newly added sub-classes and relationships. Refining the TTN database was easy because the TTN database is schema-less, which supports the iterative refinement process.

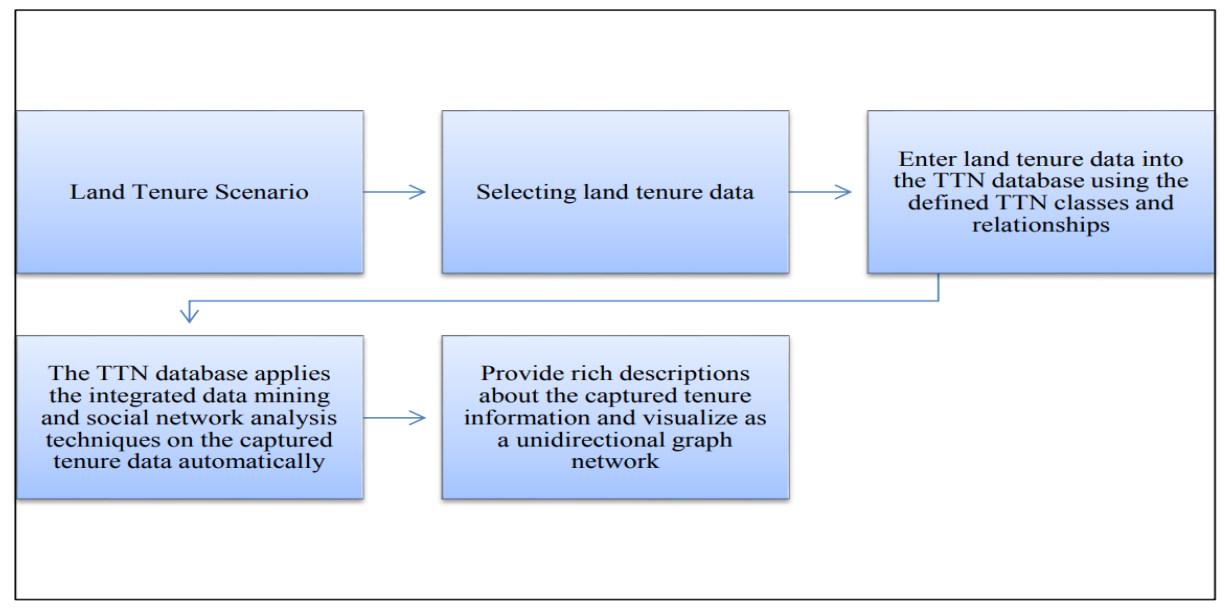

Figure 7. TTN Testing Process

The following data set (tenure scenario) was simulated by augmenting a real Gazan case with data simulated from observations in Gaza and Somaliland. The data set provides evidence for a multifaceted dispute over Ismael's land. Ismael and his descendants are members of a sub-clan of clan A. Ismail had three sons, Yousef, Omar and Khalid, and a daughter Rasha. The Ismail family owned a house in a conflict area. Ismail was the owner of "Ismhouse" and the land object "IsmLandObj01." In 2008, Ismail died. The deeds related to his land were destroyed during a conflict in 2009. The first claim was an inheritance claim submitted by Yousef's siblings against him in the Sharia court. Yousef claimed that he was the sole heir to the land and that his siblings' only interest was an occupation right to live in the house with him. Yousef supported his claim with oral testimony and unofficial documents. Contesting this, Yousef's siblings claimed that the land and the house had belonged to their father and that that they had the right to an ownership share in their father's land.

The second claim was between Yousef and Hani, and involved Ismael / Yousef 's clan (clan A) against Hani's clan (clan B). Yousef had had entered into an agreement with Hani after the 2009 conflict that Hani and Yousef would merge their land under the condition that Hani would build a new development over the merged property and assign an apartment to Yousef. The entire development was destroyed in a 2014 conflict. A dispute then arose between Hani's clan and Yousef 's clan over the merged land. Each clan submitted its claim and supporting documents to one of two courts that decide or mediate land disputes, the Sharia court which is a state institution, and the social court where disputes are mediated 
by a clan that is not part of the dispute. The choice of court was based on each party's belief about which forum was more likely to support to their case.

The authors entered the personal information and contractual information into the database. This included, for example, Yousef's personal information (e.g., full name, gender, and date of birth) and Yousef's that Yousef lives in Ismail's house. A query was then submitted as a tenure claim against the property, i.e. ID IsmLandObj01. When "Yousef" was queried the TTN database explicitly showed that Yousef is a tenant and Yousef lives in Ismail's house ID IsmHouse. Likewise, queries on other individuals revealed their status. Following this, data mining and social network analysis techniques inferred the following: Yousef owns apartment ID GroundAppartment11; Yousef submitted tenure claim ID IsmLandObj01; Yousef was part of the MergingLandObjects201110225 land operation process; Yousef's father is Ismail; Yousef is the claimant in the tenure claim ID CaseIDP201501AhDa; Yousef's siblings are Omar, Rasha, and Khalid; Yousef submitted the YousefClaimTr tenure transaction ID; and Yousef is part of the CaseIDP201501AhDa tenure dispute ID.

In the second claim, the TTN database assisted in tracing internal and external conflicts to determine key individuals, irrespective of power, as well as other influences. For instance, the social network analysis technique of the TTN database determined the key person, Yousef, who had an influential role in the internal and external disputes. Along with the social network analysis technique, data mining inferred information that helps stakeholders to gain a more comprehensive understanding of the dispute. For instance, it was revealed that Yousef had supported the amalgamation of Ismail's land object "IsmLandObj01", and Hami's land object, "HaniLandObj02." The TTN database was also able to reveal that Hani is an individual of the Tenant class, including the Person class; Hani and Yousef are parts of the land operation ID of "MergingLandObjects20110225"; Hani is part of the land dispute ID of "CaseIDP201501 AhDa"; and he is the claimer of the "HaniIsmailFamilyClaimTe2015" claim. Based on the inferred information, stakeholders can deduce that Hani is the next-door neighbour who took part in the tenure transaction that consolidated Hani's land object with Ismail's land object. Moreover, there is an additional dispute between Hani and Yousef, an open case dispute, "CaseIDP20150AhDa," that is revealed by the TTN database's integrated data mining and social networking tools. With this information, further questions are elicited, such as: Why does Yousef also own another apartment? How did Yousef obtain it? Why does Yousef have a claim for another transaction? Such questions can further assist stakeholders in investigate this particular land tenure dispute.

Analysing the above, while the data are biased by the authors having created the data, the tests show that the TTN database was able to reveal complex tenure information. TTN captured the different elements of the two claim scenarios, such as each individual in the two families, the land objects of interest, claim/tenure transaction, supporting documents, and different tenure relationships.

Thus, using the data mining and social network analysis tests, the TTN database was able to reveal hidden relationships in the data and provide a broader understanding of the constellation of interests in 
the two properties. The TTN database was also able to integrate different tenure elements due to the schema-less model of the TTN database and the integrated data mining and social network analysis techniques that make use of the Triple Store ontology languages. Moreover, the integrated data mining and social network analysis techniques assist in fraud detection processes by inferring any possible contradictions between the different items of the captured tenure information.

\section{Conclusions}

Conventional LTIS are seldom designed to support tenure security in conflict and post-conflict situations as their database design is too rigid for these situations as tenure relationships become dynamic and fluid in conflict and post-conflict situations. Relational databases incorporate schemas with many types of relationships (i.e. one-to-one, one-to-many, and many-to-many). In order to effectively update a relational database, the developer must be cognizant of how an update will affect each of these various relational types both individually and inclusively. An adaptive schema-less graph network database design model provides the flexibility to capture and describe complex tenure relationships in conflict and post-conflict situations, and developers do not have to concern themselves how updates will affect schemas. The design and simple tests described above show that the Triple Store database along with the Protégé software are suitable tools to do the initial design and testing of such a system. An advantage of the Triple Store database is it supports some data mining and social network analysis techniques automatically through its ontology languages. This is important in unearthing relationships and patterns in the data that the developers may not have considered in the initial design. In conclusion, an adaptive schema-less graph network database may be a more suitable LTIS tool in situations where data may be gathered from a variety of different sources - perhaps even starting in refugee camps while a conflict is in process, the authenticity of some of the data may be questionable if not fraudulent, system designers may not understand a number of important social relationships that pertain to tenure and this understanding evolves as data are gathered and different types of conflicts arise over time.

\section{Acknowledgement}

This research paper was funded by the Chair in Land Tenure and Cadastral Systems at the University of Calgary

\section{References}

Tamim, N 1995, 'A Historical Review of the Land Tenure and Registration in Palestine', vol. 3, no. 9, pp. 322330 
Alden Wily L 2004. Putting Rural Land Registration in Perspective: The Afghanistan Case, Proceedings of the FIG symposium on land administration in post conflict areas, Geneva, Switzerland, April 29-30, 2004, P $71-94$.

Dajani, S. 2005, Ruling Palestine: A History of the Legally Sanctioned Jewish-Israeli Seizure of Land and Housing in Palestine, Center on Housing Rights and Evictions, Netherlands, ISBN: 92- 95004-29-9

Pogrund, B. Salem, W., Scham, P., 2005, "Shared History: A Palestinian-Israeli Dialogue, Left Coast Press", California.

Augustinus C and Barry M 2006. Land Management Strategy Formulation in Post Conflict Societies. Survey Review, 38(302), 668-681.

Barry M. 2006. A Strategic Framework for Post-Conflict Land Administration Development: Hargeisa Municipality, Somaliland. UN-Habitat, Nairobi. 20 July 2006.

Butts C. 2008, "Social network analysis: A methodological introduction", Asian Journal of Social Psychology, Department of Sociology and Institute for Mathematical Behavioral Sciences, University of California, Irvine, California, USA, 11, 13-41.

Muhsen A. 2008, "Developing Multimedia Land Record Systems", university of Calgary, Canada.

Muhsen A-R., and Barry M., 2008, "Technical Challenges in Developing Flexible Land Records Software. Surveys and Land Information Science", 68(3), 171-181.

Barry M. and Bruyas F. 2009. Formulation of Land Administration Strategy in Post Conflict Somaliland. Surveys and Land Information Science. 69(1), March 2009, 39 - 52.

Strauch C. 2009, "NoSQL Databases", Stuttgart Media University, Germany.

The Overseas Development Institute (ODI), 2009, "Land tenure in conflict and post-conflict situations", ODI, last viewed at 20th of November, 2016, <https://www.odi.org/projects/346-land-tenure-conflict-post-conflictsituations>

Lemmen C. 2010, “The Social Tenure Domain Model_A Pro-Poor Land Tool”, FIG, Copenhagen, Denmark, no. 52, ISBN 978-87-90907-83-9.

ISO 2012. International Standard 19152 - Geographic information - Land Administration Domain Model (LADM), First edition, International Standards organisation.

Barry M., Molero R. and Muhsen A-R. 2013. Talking Titler: Evolutionary and Self-Adaptive Land Tenure Information System Development. South African Journal of Geomatics, Vol. 2, No. 1, 1- 12, February 2013. W3C, 2013, "W3C Semantic Web Activity", W3C, last viewed at 25th of May 2016, $<$ https://www.w3.org/2001/sw/>

Land Governance 2014, "Palestinian Territory Factsheet", IS Academy on Land Governance for Equitable and Sustainable Development, last viewed at 20 of February 2016,

Ontotext 2014, "The truth about Triplestores: the top 8 things you need to know when considering a Triplestore", ontotext.

Zaki M. Meira W., 2014, “Data Mining and Analysis”, University of Cambridge, ISBN 978-0- 521-76633-3, USA

Arafat J., Abed Al Aziz M., Al Sharif F., and Al Manama Y., 2015, “A Guide to Housing, Land and Property Law in th Gaza Strip", Norwegian Refugee Council.

Barry M. 2015. Property Theory, Metaphors and the Continuum of Land Rights, UN-Habitat / Global Land Tools Network, Nairobi.

Koek E. Arafat J. and Clutterbuck M. 2015, "Rebuilding from the Rubble: Post-conflict Land Tenure Challenges and Opportunities in the Gaza Strip", 2015 World Bank Conference on Land and Poverty, Washington DC, March 23-27. 
Zicari R. 2015, “Semantics 101”, Operational Database Management Systems (ODBMS) organization, last viewed at $18^{\text {th }}$ of August 2016, <http://www.odbms.org/2015/07/semantics101/>

Barry M. and Asiedu K. 2016. Visualising Changing Tenure Relationships: The Talking Titler Methodology, Data Mining and Social Network Analysis. Survey Review, 49 (352), 66 - 76.

Stanford University, 2016, "A free, open-source ontology editor and framework for building intelligent systems", Stanford Center for Biomedical Informatics Research, last viewed at $1^{\text {st }}$ of February, 2018, < https://protege.stanford.edu/ >

Unruh J. 2016, "Assembling evidence for a land and property restitution database during the Syrian civil war", 2016 World Bank Conference on Land and Provety, The World Bank - Washington DC, March 14-18, 2016. Dabboor A. 2017, "An Adaptive Land Tenure Information System Database Design for Conflict and PostConflict Situations”, UCGE Reports 20485, Geomatics Engineering, University of Calgary, Canada. 